\title{
Homeopathy against Malaria: It's Potential as a Third Millennium Drug
}

\author{
Aswathy Rajan ${ }^{1 *}$, Ramanibai Ravichandran ${ }^{1}$ and Upma Bagai ${ }^{2}$ \\ ${ }^{1}$ Department of Zoology, University of Madras, Chennai, India \\ ${ }^{2}$ Department of Zoology, Panjab University, Chandigarh, India \\ ${ }^{*}$ Corresponding author: Aswathy Rajan, Department of Zoology, University of Madras, Guindy Campus, Guindy, Chennai-600025, India, Tel: +91-9176964245; E-mail: \\ zoology1808@gmail.com
}

Received date: March 03, 2017; Accepted date: March 13, 2017; Published date: March 15, 2017

Copyright: @ 2017 Rajan A. This is an open-access article distributed under the terms of the Creative Commons Attribution License, which permits unrestricted use, distribution, and reproduction in any medium, provided the original author and source are credited.

\begin{abstract}
Malaria is the most devastating infectious disease in the world, and increasing numbers of multi drug resistance parasites are making it worse. The rising problem of morbidity and mortality justify the search and adoption of new tools and measures to minimize the impact of malaria. World Health Organization stated that homoeopathy is the second most used medical system internationally which is a nontoxic form of alternative medicine and can be combined with classical treatment methods for avoiding the risk of adverse effects. Innumerous scientific researches have been carried out to sustain homoeopathy as a complete scientific system to combat antagonism. Establishment of classical homeopathic drugs for malaria can prove as a next generation therapy, as homeopathy doesn't give any scope of resistance. The most important and significant aspect of homeopathic medicines is that they are developed after direct proving on human beings and not on animals. Each homeopathic medicine is therefore more akin to human nature and human system. This is a quality unshared by most medicines in other systems. This review will give scientific basis to classical homeopathic doctrine of ultra-high dilutions and their use as antimalarials. Homeopathic medicines are used against malaria since last two decades and this review provides a data of all homeopathic antimalarials and the ongoing researches. The review is supported by latest research in this field which can provide a base for designing better methodologies in the field of homeopathic antimalarial therapy.
\end{abstract}

Keywords: Homeopathy; Malaria; Potency; Antimalarial; Ultrahigh dilutions

\section{Introduction}

Mentions of malaria can be found in the ancient Roman, Chinese, Indian and Egyptian manuscripts. Morton presented the first detailed description of the clinical picture of malaria and its treatment with Cinchona. He also suggested that the disease is produced by some poison which enters the body [1]. The Cinchona (china) bark testing for malaria patient gave birth to homeopathy. Dr. Hahnemann (Father of homeopathy) theorized that because the bark produced symptoms similar to malaria, taking a small amount of bark would stimulate the body to heal itself of malaria, after which the principle of "similia simibilus currentur"-like cures like was established in homeopathy [2]. Homeopathy has been cited by the World Health Organization as one of the systems of traditional medicine that should be integrated with conventional medicine to ensure adequate global healthcare $[3,4]$. According to homeopathy, the body's symptoms of illness are an expression of the body trying to heal itself and should not be suppressed. Homeopathic remedies help in establishing balance in body and promote its ability to heal itself. It intervenes at the level of person's reactive, self-curative powers with a goal to bring about a change in the total functioning of the body. Homeopathy regards disease as deranged vital process, caused by dynamic influences of noxious agents of the vital principle, as manifested through perceptible sign and symptoms. According to homeopathic thought the pathogens are carriers of dynamic specific traits of respective disease force which only can affect the vital force of the susceptible living host in a suitable environment producing corresponding change in the function and structure of the physical body of the host, totality of which is named as particular disease [5].

The homeopathic approach may be useful specifically because it does not focus on the cause of the disease but on the teleonomy of the patient's reaction. It is therefore not being considered an alternative approach by many homeopaths, but complementary to effective drug use [6]. From the time of its birth, in recent years homeopathy has evolved in clinical, physical, chemical, biological and medical levels with acceptable scientific norms. Homeopathic drugs have been claimed for their efficacy, without side effects and low cost and they have been evaluated for their suitable candidature as potent antimalarials. This review gives an insight about the growth of ancient homeopathy which was based on human proving to cellular/ subcellular level studies.

\section{Materials and Methods}

The data was collected from all the published research articles, reviews and newsletters available during the period of 2007-2015. Various articles were collected from E-journals like Homeopathy 4 everyone and Homeopathy Ezine. The books related to organon and philosophy, therapeutics and Materia Medica were consulted and all the data were collected from them.

The collected data were thoroughly studied and documented year wise. The list of homeopathic remedies used for malarial/malaria like fevers were taken from various homeopathic repertories by different homeopaths for the preparation of the table. 


\section{Malaria in history of homeopathy}

Malaria generally presents a multifaceted expression, typically by the three phase paroxysm associated with auxiliary symptoms besides cachexia or background symptoms on becoming chronic. This is due to the different developmental stages of the parasite in the human body. Each of the stages could contribute its respective toxins, resulting in the typical paroxysmic phases and their concomitants. Consequently, selection of similimum has been problematic which continues even today. Hahnemann having himself been the first formal prover of quinine which led him to found homoeotherapeutics, was quite seized of the problem [7].

Cinchona was the first antimalarial medicine based on similia principle; later on it was established as quinine. There was a continuous but unnoticed progress in homeopathic antimalarial research since its birth. It is important to know the background and its course of development during the past to establish the identity of the ultra-high dilutions of homeopathy.

\section{Late $18-19^{\text {th }}$ century}

Allen reported over 100 malarial cases cured by 50 homeopathic medicines based on a review of the literature in 1884 [8] (Table 1). Temple and Hoyne likewise dealt with results of over 50 cases treated by about 25 homeopathic drugs in 1878 [9], while Clarke listed out over 100 drugs clinically confirmed as curing intermittent fevers in 1904 [10].

Many others also provided periodical reviews of literature in homeopathic treatment for intermittent fever. Most frequently used homeopathic remedies for malaria treatment include: Arsenicum album, Bryonia, Ipecacuanha, Eucalyptus globulus, Natrum muriaticum and Veratrum album [11,12]. Fenner has listed 45 homeopathic remedies which can be used for malaria [13] and Puhlmann has added few more to the list [14]. Recent data bases lists 130 remedies which can be used for the treatments depending upon the individual's symptoms, as every patient can have different accompanying signs to his classical symptoms of malaria. The treatment is individualized according to the inter-individual differences. Kent also prescribed Ars., Calc- ar., Ferr., Psor., Sulph. and Tub. For relapsing fever whereas; Ars., Bell., Chin., Eup- per., Verat., Sulph. and Rhus- t. are recommended for remittent fever [15]. Malaria like many other ailments in chronic state becomes metastatic, expressing itself in different forms in different parts of the body and in such cases the chill may be experienced in only certain body parts.

According to Hughes, malarial toxaemia essentially involves silencing of the oxidative mechanism in one or more parts of the body and leads to sensation of chills in the parts concerned and finally their dysfunctioning due to non-availability of the energy supplies, which has potential to bring an end to the life of the host. Therefore such drugs which can review the oxidation in varied parts of the body would form the appropriate remedies. Apparently polychrests like Ars.,
Calc- ar., Chin- a. (remedies for malarial cachexia) which can kindle oxidation would be useful. Ars. is more deep acting and helped in successful treatment of malarial cachexia. Thus in chronic cases such drugs could be effective than not only polychrests, high oxidants but also deep acting being able to penetrate remote parts of the body like the nerves, bones and various glands [16].

In an open-double blind randomized clinical trial for malaria in Ghana following homeopathic remedies were used: Arsenicum album, china, Eupatorium perfoliatum, Natrum muriaticum, Nux vomica, Pulsatilla, Rhus toxicodendron and Sulphur. Chloroquine was used as standard drug in placebo control group. The percentage of $90.7 \%$ improvement in open study and $83.3 \%$ in double blind study has been attributed to the homeopathic treatment, during the four week study period. However, a definite conclusion can be drawn if study is extended for a longer follow-up period (minimum 6 months) to access the number of episodes comparing the chloroquine group with homeopathic group [17].

Patients with $P$. falciparum malaria showed rapid response in the medication with Sulphur 200 and $1 \mathrm{M}$ and for over 3 months no relapse was reported [18]. For irregular types of cases which are already treated with allopathic or homeopathic or any drug therapy, and in such cases more often two or more remedies are recommended. In such cases it is essential to antidote the picture of the earlier drugs. Ip. or Ars. or Nux- v. can be useful. He also reported Chininum arsenicosum (1X, 2X, 3X, 6X), Chininum sulphuricum (1X, 2X, 3X, $6 \mathrm{X}$ ) and Chininum purum (Q, 1X, 2X, 3X, 6X) against malarial poisoning. Natrum suphuricum (3X,6X), Aranea diadema $(\mathrm{Q}, 6 \mathrm{C})$ and Ceanothus americanus (Q) which act as drainage in malaria, Echinaecia angui (Q), Nyctanthes arbortristis (Q), Baptisia tinctoria (Q), Melia azardichata (Q) and Eupatorium perfoliatum (Q) are prescribed for relieving concomitant peripheral and toxic symptoms of malaria are used to remove Plasmodium species from blood. They also act as blood purifier and drainage remedy [19].

Central council for research in homeopathy and AYUSH, India gave homeopathic medicines: Eupatorium perfoliatum, Alstonia constricta, Chin- a., Chin- s., Ars. as preventive medicines for malaria in Rajasthan (Jaipur, Bikaner, Jodhpur, Barmer and Jaisalmer), whereas one more drug Verat was given for the treatment. For the persons going to malarious regions, homeopathic medicines Chin- a. $3 \mathrm{X}$ with Nat- s. $6 \mathrm{X}$ and Ferr. 12X two times in day or the same at increasing intervals during the stay is recommended as preventive dose [19].

\section{In $20^{\text {th }}$ century}

Robin Murphy recommended in his homeopathic medical repertory, Abies-n., Arg- n., Aran., Carb- ac., Chin., Chin- a., Chin-s., Eup-per., Ferr., Ip., Nat- m., Nat- s., Nux-v., Psor., Sulph., Ter., Verat. for the malarial fever, Eucal., for chronic and relapsing malaria. Malaria co nosode 30 is also recommended for recurring parasite which lingers in liver for months [20].

\begin{tabular}{|l|l|l|l|}
\hline S. No. & Name of Authors & Year & Proposed Drugs \\
\hline 1 & Nash EB & $1807-1913$ & Ars., Chin., Eup- perf., Gels., Ip., Nat- m., Podo., Puls., Rhus- t., Sabad. \\
\hline 2 & Temple \& Hoyne & 1878 & $\begin{array}{l}\text { Apis., Aran., Arn., Ars., Cact., Calc- ar., Camph., Caps., Chin., Cina., Gels., } \\
\text { Helle., Ip., Lyc., Mer- C., Nat- m., Nux- v., Op., Petr., Puls., Rhus- t., Sars., } \\
\text { Sep., Stram., Sulph., Thuj. }\end{array}$ \\
\hline
\end{tabular}




\begin{tabular}{|c|c|c|c|}
\hline 3 & Allen $\mathrm{HC}$ & $1879 \& 1884$ & $\begin{array}{l}\text { Apis., Ars., Bapt., Bry., Chin., Chin-.s., Eup- perf., Gels., Ign., Lach., Nat- m., } \\
\text { Nux- v., Op., Sulph. }\end{array}$ \\
\hline 4 & Farrington EA & 1880 & $\begin{array}{l}\text { Apis., Ars., Arn., Camph., Carb- ac., Chin- a., Chin., Crot- h., Ipec., Lyc., } \\
\text { Mur- ac., Nux- v., Psor., Pyr., Sulph., Sulph- ac., Verat. }\end{array}$ \\
\hline 5 & Kent JT & 1888 & $\begin{array}{l}\text { Ant- c., Arn., Ars., Bapt., Bry., Colch., Eup- perf., Gels., Hyos., Ip., Lyc., Mur- } \\
\text { ac., Rhus- t. }\end{array}$ \\
\hline 6 & Wrumb & - & Ars., Ign., Ip., Nux- v., Puls., Verat. \\
\hline 7 & Clarke & 1904 & $\begin{array}{l}\text { Apis., Aran., Ars., Aza., Bry., Cact., Calen., Carbo- v., Carb- ac., Cean., } \\
\text { Ced., Chin- a., Chin.,Chin- m., Chin- s., Corn., Elat., Eup- perf., Eup- purp., } \\
\text { Ferr., Gels., Lach., Lyc., Malar., Meny., Nat- m., Nux- v., Puls., Rhus- t., } \\
\text { Sulph., Verat. }\end{array}$ \\
\hline 8 & Boger CM & 1905 & $\begin{array}{l}\text { Aran., Ars., Caps., Ced., Eup- perf., Ign., Nat- m., Nux- v., Ph- ac., Puls., } \\
\text { Sulph., Verat. }\end{array}$ \\
\hline 9 & Mills & 1915 & $\begin{array}{l}\text { Ars., Alst- s., Am- pic., Aran., Caps., Chin., Chin- a., Chin- s., Corn., } \\
\text { Helianth., Ip., Nat- m. }\end{array}$ \\
\hline 10 & Josset & - & Ars., Caps., Ip., Nux- v. \\
\hline 11 & Boericke W & 1927 & $\begin{array}{l}\text { Ars., Alston., Am- pic., Aran., Caps., Chin., Chin- a., Chin- s., Corn., } \\
\text { Helianth., Ip., Nat- m. }\end{array}$ \\
\hline 12 & Bernoville & 1936 & Ars., Cean., Chin., Chin- a., Nat- m. \\
\hline 13 & Kichlu \& Boss & 1988 & Ars., Bry., Chin., Chin- s., Eup- perf., Ferr., Gels., Nat- m., Nux- v., Puls. \\
\hline
\end{tabular}

Table 1: Homeopathic drugs proposed by various authors as the most effective antimalarials.

It is also reported that a 3 week course of Neem $2 \mathrm{X}$ tincture can neutralize the parasite, expel it and help eliminate the chronic malaria. The follow-up monthly dose of Malaria nosode is a backup to further protect the person and help to remain free of malaria [21]. There is also in the recent literature, some works designed to explore the behavior of the body after to be stimulated by parasitic stressor and treated with homeopathic medicines. It is also recommended to take a homeopathic first aid kit for travelers to Africa containing Chin- s, Chin. with Art. and quinine [22].

Some other homeopathic formulations like Calcarea arsenicosum, Capsicum, Carbolicum acidum, Cedron, Ferrum picricum and Ignatia are also recommended for intermittent fevers [23]. The nosode Malaria Co., a compilation of malarial parasites species ( $P$. falciparum, $P$. vivax, $P$. ovale and $P$. malariae) is a prescription remedy that can be used alternately with Chin., Nat- m., Phosphorus, Ars. and Eup- pru. Starting with a single dose of Nat- m. 30C, single dose of Chin. 30C in the following week, followed by a dose of Phosphorus 30C in next week with a final single dose of Arsenicum 30C in the last week of the cycle can be very effective. If one stays for an extended time in a highrisk area, these remedies can be administered in a 200C less frequently [23]. These remedies in a 30C dose can be alternated weekly prior to visiting an endemic area. A complex mixture of 'Malaria $\mathrm{X}$ ', a preparation of $30 \mathrm{C}$ remedies which contains 5 ingredients (Malaria nosode and 4 other remedies- China officinalis, Natrum muriaticum, Arsenicum album and Eupatorium perfoliatum) is very effective in malarial attacks and also in preventing malaria. Other remedies useful for the prevention of malaria include Natrum muriaticum, Phosphorus or Arsenicum. Malaria officinalis and Eupatorium prupurem, have also been used as preventative remedies [23].

In Kenya, Abha Light Foundation has been working in the field of malaria for 10 years, treating the disease with homeopathy and natural medicines. They developed a protocol of homeopathic medicines for all-round prophylaxis treatment. According to them, homeopathic formulation of Neem ( $2 \mathrm{X}$ or D2) has proven its effectiveness in eliminating recurring malaria. Five drops a day for $2-3$ weeks is believed to destroy any parasite that may remain in the body and breaks the cycle of recurrent malaria. Neem $2 \mathrm{X}$ still continues to be given successfully to thousands of Masai tribals in Tanzania [24]. It was also reported that, at many clinics in Kenya, Malaria X is a regular prescription for hundreds of patients. In a Kendu Bay Malaria prevention project in Kenya, Malaria X (3-step program) was distributed to 1500 families. Six months before starting the program, $100 \%$ of participants had attacks of malaria or malaria-like symptoms at least once in their lifetime. Of the 34 participants $71 \%$ used to get malaria or malaria like symptoms once a month or every two weeks. Since starting the 3 -step program, only $12 \%$ (4 out of 34 ) respondents had an attack of malaria or malaria like symptoms [24].

For the treatment of malaria, depending on the specific Plasmodium species and the mainifestation of disease, Phosphorus, China sulphuricum, Chin., Ferrum metallicum, Arsenicum, Lycopodium, Tuberculinum, Natrum muriaticum and Malaria officinalis are more indicated. Phosphorus is indicated if there is marked liver involvement and yellowing of the skin; China sulphuricum when there is marked destruction of the red blood cells; Chin. where the periodicity of fever chills and perspiration is more marked; Ferrum metallicum when there is complete exhaustion from the anemia; Lycopodium when the disease has caused a weakening of the liver and kidneys and there is gas and abdominal bloating; Tuberculinum with intermittent fever, cachexia and weak lungs; Natrum muriaticum in cases of cachexia, chlorosis, emaciation and irregular intermittent fevers; Malaria officinalis to reduce the amount of live Plasmodium in the blood [23]. 
An embracing change was witnessed in the field of homeopathic research in the beginning of 20th century. Till now homeopathy was based on human provings, but use of other animal models for homeopathic research was a boon to researchers. Mice (Mus musculus) have been used as experimental model in homeopathic research in relation to cytotoxicity, genotoxicity and carcinogenesis studies as they share a high degree of homology with humans [25]. Salazar et al. demonstrated the effect of Eupatorium perfoliatum 30C and Arsenicum album 30C on Plasmodium berghei infected mice. Parasite multiplication was inhibited, but the most interesting observation was the increase in the number of schizonts suggesting an interruption of Plasmodium life cycle in this intracellular phase [26]. But this study was not able to find a mechanism of action of the treatment. In another study, a homeopathic medicine Eucalyptus was given in combination with allopathic medicine artesunate for clearing blood stage infection of $P$. berghei in $\mathrm{BALB} / \mathrm{c}$ mice. The combination has been reported to provide a mutual protection and also protected recrudescence up to the one month follow up period [27]. Rats are also commonly used animal for homeopathic research featuring in around 67 experiments indexed in HomBRex database [28]. Both isopathic and Similia principle models seem useful to understand complex biological phenomena, such as host-parasite intractions and the effects of high dilutions seem to tend to restore living systems to a 'stable state', recovering normal parameters similar to control, as seen in several experimental models from both, descriptive and mathematical modeling points of view [29].

Within a decade many preliminary studies were carried out to check antimalarial activities of various homeopathic formulations. In a preclinical study, the combination it was confirmed that oral administration of china $\varphi$ and china 30C in monotherapy for 7 days lead to complete inhibition of parasite load in $P$. berghei infected $\mathrm{BALB} / \mathrm{c}$ with increased survival rate $(26.8 \pm 1.2$ days $)$ of mice. Both showed high efficacy when given in combination with artesunate (100 $\mathrm{mg} / \mathrm{kg}$ ). The therapeutic efficacy of the combination was confirmed by the stable levels of hepatic and renal markers in serum after treatment. This homeopathic regimen was reported to be better than the standard ACT (Artesunate+Sulphadoxine/Pyrimethamine) [30]. The homeopathic remedies were found to be effective on various parameters of study on mice. The viability and integrity of blood cells were also studied using Scanning electron microscopy and acridine orange staining and were found normal after the treatment [30]. Histochemical studies also revealed hepatoprotective and nephroprotective role of homeopathic formulations in $\mathrm{P}$. berghei infected $\mathrm{BALB} / \mathrm{c}$ mice [31].

In a similar study, mother tincture of Chelidonium majus and its potencies i.e., 6, 30 and 200 were found to exhibit considerable antiplasmodial activity against blood stage infection of $P$. berghei in mice and 30C was reported to enhance the maximum Mean Survival Time (MST) of mice [32]. Another homeopathic medicine, Malaria Co Nosode 30 was also reported to possess considerable antimalarial potential with $87.02 \%$ chemosuppression against $P$. berghei infection in $\mathrm{BALB} / \mathrm{c}$ mice. Nosode is a homeopathic preparation of the secretion from the affected area/tissue. The drug was also found to be safe on liver and kidney functions of the host as observed by the normal levels of liver and kidney markers in serum of treated mice [33]. Contrary to homeopathic principle, recently another research proved that the combination of homeopathic formulations can be used for therapeutic purposes. The combination of $30 \mathrm{C}$ of china and Chelidonium was reported to possess potent antiplasmodial effect in mice [34].
In vitro techniques with homeopathic potencies are newer and more convenient method of checking efficacy of various homeopathic antimalarials. In recent times many such notable studies have been undertaken. Rajan and Bagai have also reported effective schizont maturation inhibition by some homeopathic drugs in in vitro system [35]. This kind of studies clearly shows that homeopathy can be coupled with latest techniques to procure more valuable scientific data.

\section{Discussion}

From the available literature and data from countable research publications on antimalarial homeopathic formulations, it is evident that classical documentation is still not practically followed everywhere. The publication of laboratory investigations of ultra-high dilutions in homeopathy has produced considerable controversy and mixed results on attempted replication [36,37]. Still, unusual effects of ultra-high dilutions in rigorous laboratory studies continue to be reported [38,39]. Multiple independent replications of this research have not yet been done because there are few investigators in the field [40]. Future research should focus on simple clinical or laboratory models that can be easily attempted by multiple investigators. In addition, better data are needed to examine the use and effects of homeopathy by the public and in actual practice [41-43]. The classically documented doctrine need to prove its potential through evidence based scientific research.

The scientific community entirely misses the boat on the treatment of infectious diseases. The approach itself is defective. One of the major defects in the conventional approach is the futile search for the socalled 'active ingredient' in any natural substance in order to isolate it, analyze it and then chemically synthesize it in order to mass produce it. Whereas, herb or natural substances (as used in homeopathy) has not one but thousands of active ingredients working together, that make whole herbs still the most effective means of treating infectious diseases, including so-called resistant malaria [24].

Homeopathy is the second largest system in the world, widely used and economical but lacks some evidence based research and data in order to prove its efficacy to the scientific community. Despite of so many latest developments in the field of homeopathic research there is certainly a missing link between the existence of active molecules in these ultra-high dilutions and its efficacy. According to hypothesis given by Khuda-Bhuksh, potentized homeopathic drugs have also been tested against many toxic chemical compounds. These potentized homeopathic medicines are capable of acting by triggering the regulatory action of master genes which initiates a series of reactions, resulting in many cellular and subcellular changes [25].

\section{Conclusion}

Despite being successfully used in many countries, homeopathy still gives a scope of doubt because of some scientific loop holes. As a result it is not accepted by whole scientific community. The modes of action of homeopathic dilutions are still a darker area in homeopathic research. Need of Randomized control trials on human subjects to prove safety and efficacy of homoeopathic drugs is the only way to get answers to many hypothesizes. In future strong scientific basis will be needed to establish homeopathy as a medicine of the 3rd millennium. 


\section{Acknowledgments}

This study was supported by young scientist startup grant (YSS/ 2014/000290) to Aswathy Rajan from SERB (DST), New Delhi, India.

\section{References}

1. Morton R (1696) Exercitationes de morbis universalibus acutis. Ed ult Venice; Typis Hieronymi Albuzzi.

2. Hahnemann S (1960) Introduction to homeopathy. In: Organon of Medicine. (First Indian edn). Haehl R, M. Bhattacharyya and Co. (eds), Pub, Calcutta, pp. 1-300.

3. Bannerman RH, Burton J, Wen Cheih C (1983) Traditional medicine and health care coverage. World Health Organization, Geneva Switzerland.

4. World Health Organization (2000) The Priscriber. Promoting rational use of drugs and correct case management in basic health services. UNICEF's Programme Division in cooperation with the World Health Organization 18: $1-16$

5. Shah H (1999) Intermittent Fever. In: Malaria and Homeopathy. Shah H and Jain M, (eds), Indian Books and Periodicals Pub, New Delhi, pp. 1-233.

6. Bellavite P, Ortolani R, Pontarollo F, Pitari G, Conforti A (2007) Immunology and Homeopathy, The Rationale of the 'Similie'. Evid Based Compl Alternat Med 4: 149-163.

7. Ramayya N (1994) Perspectives in Homeopathic Treatment of Malaria. National J Homeo 3: 1-6.

8. Allen HC (1884) Malarial fever. In: The therapeutics of intermittent fever. Claude RN, (ed), Hahnemann Pub, Calcutta pp. 1-342.

9. Temple S, Hoyne AM (1878) Therapeutics for intermittent fevers. In: Clinical therapeutics in homeopathy, Vol. 1, Richard D and Dake ES (eds), B Jain Pub, New Delhi pp. 1-583.

10. Clarke JH (1904) Malarial fever. In: Clinical Repertory to the Dictionary of Materia Medica. Clarke JH, (ed), B Jain Pub, New Delhi pp 1-325.

11. Kent JT (1974) Malaria. In: Repertory of the Homeopathic Materia Medica, Kent JT, (ed), Harjeet and Co Pub, New Delhi pp 1-115.

12. Farrington EA (1989) Fever. In: Comparative Materia Medica, Farrington EA, (ed), B Jain Pub, New Delhi pp. 30.

13. Fenner G (1925) Malaria. In: Tropenkrankheiten, Gaucher C, (ed) Schwabe Pub, Leipzig pp. 220-435.

14. Puhlmann (1920) Homeopathic remedies for malaria. In: Handbuch der homeoÖpathischen praxis, Hangstebeck T. (ed), Schwabe Pub, Leipzig, pp. 112-118.

15. Kent JT (1989) Relapsing Fever. In: Reportory of the homeopathic Materia Medica. Kent JT, (ed), B Jain Pub, New Delhi pp. 1-233.

16. Clarke JH (1986) Intermittent fevers. In: A dictionary of practical material medica, Vol. 1, Clarke JH, (ed), B Jain Pub, New Delhi pp. 1-951.

17. Van Erp VMA, Brands M (1993) Malaria and homeopathic remedies in Ghana, an open study and a double-blind randomized clinical trial. Homeopathy 5: 312-316.

18. Ramayya N (1994) Perspectives in homeopathic treatment of malaria. National J Homeo 3: 1-6.

19. Shah H (1999) Intermittent Fever. In: Malaria and Homeopathy. Shah H and Jain M, (ed), Indian Books and Periodicals Pub, New Delhi pp. 1-233.

20. Robin Murphy (2004) Fever-heat. In: Homeopathic Medical Repertory. Robin Murphy, (ed), B Jain Pub, New Delhi pp. 822-861.

21. Partington T, Ruchira DA, Hennel L, Pittendrigh A, Taylor J (2006) Silent and deadly, prophylaxis and treatment of malaria. Homeo in prac Spring 14-19.

22. Peter C (2007) Interviews with Homeopaths. Homeopathy 4 everyone 5: 11-13.

23. Birch K (2007) Malaria. In: vaccine free prevention and treatment of infectious contagious disease with homeopathy. Burch M, Über R, Robert Lee D, (eds), Trafford Pub, Bloomington pp. 351.
24. Ruchira DA (2010) The use of homeopathic prophylaxis and treatment for malaria in endemic areas of Kenya. Homeopathy 4 everyone 7: 23-26.

25. Khuda-Bukhsh AR (2009) Mice as a model for homeopathy research. Homeopathy 98: 267-279.

26. Salazar GL, Montiel EM, Monzon JT, Hernandez FH, Salasbenito JS (2006) Effects of homeopathic medications Eupatorium perfoliatum and Arsenicum album on parasitaemia of Plasmodium berghei infected mice. Homeopathy 95: 223-228.

27. Bagai U, Rajan A, Chandel S (2008) Efficacy of Eucalyptus (a homeopathic medicine) in combination with artesunate to clear Plasmodium berghei infection in BALB/c mice. In: Tandon V, Yadav AK, Roy B (eds) Current Trends in Parasitology, Proceedings, 20th National Congress of Parasitology, November 3-5-2008, NEHU, Shillong, India pp. 203-211.

28. Fisher P (2009) Biological models of homeopathy. Homeopathy 98: 183-185.

29. Bonamin LV, Endler PC (2010) Animal models for studying homeopathy and high dilutions: Conceptual critical review. Homeopathy 99: 37-50.

30. Rajan A, Bagai U (2011) SEM studies on blood cells of Plasmodium berghei infected BALB/c mice treated with artesunate and homeopathic medicine china. J Parasit Dis 35: 134-139.

31. Rajan A, Bagai U, Chandel S (2013) Effect of artesunate based combination therapy with homeopathic medicine china on liver and kidney of Plasmodium berghei infected mice. J Parasitic Dis 37: 62-67.

32. Rajan A, Bagai U (2013) Ameliorating effect of homeopathic medication Chelidonium majus 30c on Plasmodium berghei infected balb/C mice. AJHM 106: 125-131.

33. Bagai U, Rajan A, Kaur S (2012) Antimalarial potential of nosode 30 and 200 against Plasmodium berghei infection in $\mathrm{BALB} / \mathrm{c}$ mice. J Vector Borne Dis 49: 72-77.

34. Rajan A, Bagai U (2013) Antimalarial potential of China 30 and Chelidonium 30 in combination therapy against lethal rodent malaria parasite: Plasmodium berghei. J Complement Integrated Med 10: 1-8.

35. Rajan A, Bagai U (2012) Antimalarial potential of homeopathic medicines against schizont maturation of Plasmodium berghei in shortterm in vitro culture. Int J High Dilution Res 11: 224-236.

36. Davenas E, Beauvais F, Amara J, Oberbaum M, Robinzon B, et al. (1988) Human basophil degranulation triggered by very dilute antiserum against IgE. Nature 333: 816-818.

37. Ovelgönne JH, Bol AW, Hop WC, van Wijk R (1992) Mechanical agitation of very dilute antiserum against IgE has no effect on basophil staining properties. Experientia 48: 504-508.

38. Linde K, Jonas WB, Melchart D, Worku F, Wagner H, et al. (1994) Critica review and meta-analysis of serial agitated dilutions in experimental toxicology. Hum Exp Toxicol 13: 481-492.

39. Jonas WB, Kaptchuk TJ, Linde K (2010) Academia and clinic: A critical overview of homeopathy. Ann Intern Med 1-11.

40. Vickers AJ (1999) Independent replication of pre-clinical research in homeopathy: A systematic review. Forsch Komplementarmed 6: 311-320.

41. Linde K, Clausius N, Ramirez G, Melchart D, Eitel F, et al. (1997) Are the clinical effects of homeopathy placebo effects? A meta-analysis of placebo-controlled trials. Lancet 350: 834-843.

42. Linde K, Jonas WB (1999) Evaluating complementary and alternative medicine: the balance of rigor and relevance. In: Essentials of Complementary and Alternative Medicine. Jonas WB and Levin JS (eds), Lippincott Pub, Philadelphia pp. 57-71.

43. Jonas WB, Anderson RL, Crawford CC, Lyons JS (2001) A systematic review of the quality of homeopathic clinical trials. BMC Complement Altern Med 1: 12-17. 